\title{
Pregnancy with Elephantiasis Neurofibromatosa-A Rare Presentation
}

\author{
Monika Gupta1 ${ }^{*}$, Vipan Gupta², Kamini Sapre³ ${ }^{3}$, Sushmita Sharma ${ }^{4}$, Prithpal S. Matreja ${ }^{\text {* }}$ \\ ${ }^{1}$ Department of Obstetrics and Gynecology, Maharishi Markandeshwar Institute of Medical Science and \\ Research, Solan, India \\ ${ }^{2}$ Department of Otorhinolaryngology, Maharishi Markandeshwar Institute of Medical Science and Research, \\ Solan, India \\ ${ }^{3}$ Department of Obstetrics and Gynecology, Medical College and Sir Sayajirao General Hospital, Baroda, India \\ ${ }^{4}$ Department of Obstetrics and Gynecology, Gian Sagar Medical College and Hospital, Patiala, India \\ ${ }^{5}$ Department of Pharmacology, Gian Sagar Medical College and Hospital, Patiala, India \\ Email: drmonikasingla@gmail.com, drvipan@yahoo.com, ksapre123@gmail.com, \\ sushmitasharma28@gmail.com, ${ }^{*}$ drpsmatreja@yahoo.co.in
}

Received 25 August 2014; revised 5 October 2014; accepted 12 November 2014

Copyright () 2014 by authors and OALib.

This work is licensed under the Creative Commons Attribution International License (CC BY).

http://creativecommons.org/licenses/by/4.0/

(c) (i) Open Access

\begin{abstract}
Neurofibromatosis (NF1) is an autosomal dominant disorder primarily affecting the development and growth of nerve cell tissues. We report a rare case of pregnancy with giant plexiform neurofibroma involving the genital tract with adverse perinatal outcome. A 26-year-old female presented at term in labour with NF1 and a huge plexiform neurofibroma arising from sacral region, gluteal region, pelvis and involving left labium majus. She delivered by cesarean section and the baby had congenital NF1. The baby expired on day 4 of life. To the best of our knowledge, this large size neurofibroma involving this site in pregnancy has never been reported in English literature. Both pregnancy and NF1 have reciprocal adverse effects on each other. Congenital neurofibromatosis can be fatal. Hence, all pregnancies associated with NF1 should be considered as high risk and monitored carefully.
\end{abstract}

\section{Keywords}

Plexiform Neurofibromatosis, Congenital Neurofibromatosis, Stillbirth, Perinatal Outcome, Elephantiasis Neurofibromatosa, Neurofibromas

Subject Areas: Evidence Based Medicine, Gynecology \& Obstetrics

${ }^{*}$ Corresponding author.

How to cite this paper: Gupta, M., Gupta, V., Sapre, K., Sharma, S. and Matreja, P.S. (2014) Pregnancy with Elephantiasis Neurofibromatosa-A Rare Presentation. Open Access Library Journal, 1: e985. http://dx.doi.org/10.4236/oalib.1100985 


\section{Introduction}

Neurofibromatosis, first described by the German pathologist Frederich Von Recklinghausen, is a hereditary neurological disorder. Without special predilection for race or sex, neurofibromatosis type 1 (NF1) is a multisystem disease with an incidence of 1:3000 having autosomal dominant inheritance, 100\% penetrance, variable expressivity and wide range of pathogenic mutations [1]. Sporadic cases result from high gene mutation rate. NF-1 gene is located on chromosome 17.

The diagnosis of NF1 is made on the basis of clinical features requiring the presence of at least two of the following major criteria [2]: 6 or more café-au-lait spots (CALS); axillary or inguinal freckling; two or more cutaneous neurofibromas; one plexiform neurofibroma; characteristic bony defects; optic glioma; two or more iris Lisch nodules; or a first-degree relative with NF1 [3] [4].

The incidence in pregnancy is very less and occurs in 1:2434 to 1:18,500 deliveries [5] [6]. The earliest description of neurofibromatosis in association with obstetrics was probably given by Brickner in 1906.

Perinatal complications are reported to be higher in this group of patients and these should be regarded as high risk cases. NF1 directly or indirectly adversely affects the outcome of pregnancy [7].

\section{Case Report}

A 26-year-old $3^{\text {rd }}$ gravida presented with 9 months amenorrhea, leaking per vaginum and abdominal pain for 13 hours. She belonged to a low socio-economic group and there was no history of antenatal check-ups. Patient had multiple lesions all over the body since 7 years of age, and a large swelling over back, involving buttocks and genital region for last 10 years, gradually increasing in size. It was causing difficulty in walking, sitting, lying down and carrying out daily household activities for 2 years. It increased in size more rapidly over a period of 1 year since the patient got pregnant. There was no history of seizures or bladder and bowel disturbances. Her first baby was a male, 7 years of age, and had no stigmata of the disease. Second was a preterm vaginal delivery of a still born female at gestation of 8 months conducted at home, 2.5 years back. No records were available regarding that delivery and baby. She had 4 sisters and one brother who did not have any disease according to the patient.

On physical examination, she had multiple café-au-lait macules of varying sizes and neurofibromas all over the body. There was pigmentation present over sclera, buccal mucosa and palms. A huge plexiform neurofibroma of $68 \times 30 \times 15 \mathrm{~cm}$ size, as a diffuse elongated swelling arising from sacral region in midline in form of loose folds of skin involving gluteal region, obliterating the inter-gluteal cleft, involving left side of vulva, perineum and displacing anal orifice away from midline (Figure 1). Clitoris appeared normal. A $10 \times 10 \mathrm{~cm}$ decubitus ulcer was present over dependent aspect of swelling. The mass was so huge so as to make patient uncomfortable lying down in the supine position and also to perform examination and surgery (Figure 2). On per abdomen examination, fundal height was almost 34 weeks and per speculum examination was not possible. On per vaginal examination, she was in advanced labour with high station of head and soft tissue bulge was felt posteriorly and towards left in the pelvis leading to non-progress of labour. There were Lisch nodules present around iris in left eye and ENT check up revealed no abnormality.

Lower segment cesarean section was performed as the huge soft tissue swelling involving vulva and pelvis caused non-progress of labour with fetal distress. The surgery was performed under general anaesthesia, delivering an alive term female of 2600 gms with severe birth asphyxia having APGAR-3/5/7 with neurofibromatosis. She was having 7 café-au-lait macules (Figure 3) and one of them was more than $1 \mathrm{~cm}$ in diameter. The new born was having micro-opthalmia and Lisch nodules in the left eye. Post-natal scans showed diffuse intracranial calcifications too. The baby died on $4^{\text {th }}$ day of life due to septicemia in spite of treatment.

Post-natally, ultrasound of local area showed heterogeneous lesions with multiple linear echogenic strands within it. Multiple subcutaneous hypoechoic lesions were seen p/o neurofibromatosis with no malignant transformation. USG abdomen and pelvis were normal. CT scan of head was normal with no intracranial tumors. Chest X-ray, X-ray lumbosacral Spine, X-ray pelvis and hip were also normal. Wedge biopsy was performed postnatally and sections showed marked fibrosis of dermis and subcutis. Some vascular proliferation was present.

Patient was discharged on $7^{\text {th }}$ post-op day after stitch removal. On follow up after 4 weeks, size of the neurofibroma had reduced and patient was referred to plastic surgeon and surgical excision was done reducing the size of the swelling. 


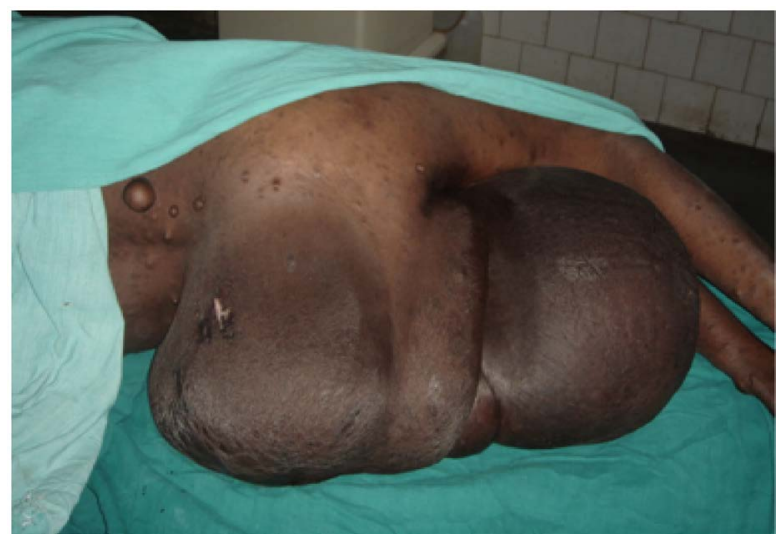

Figure 1. Giant plexiform neurofibroma arising from sacral region along with multiple small neurofibromas.

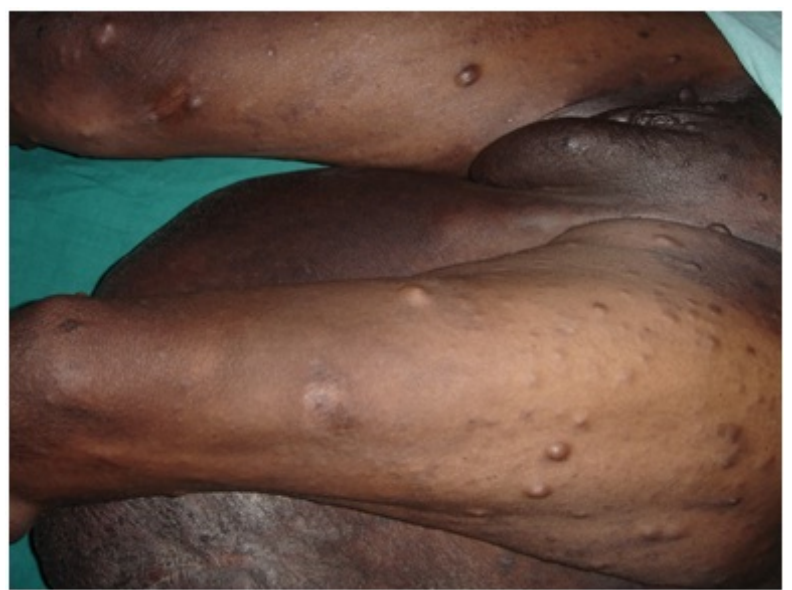

Figure 2. Giant plexiform neurofibroma involving left labium majus and patient lying in supine position.

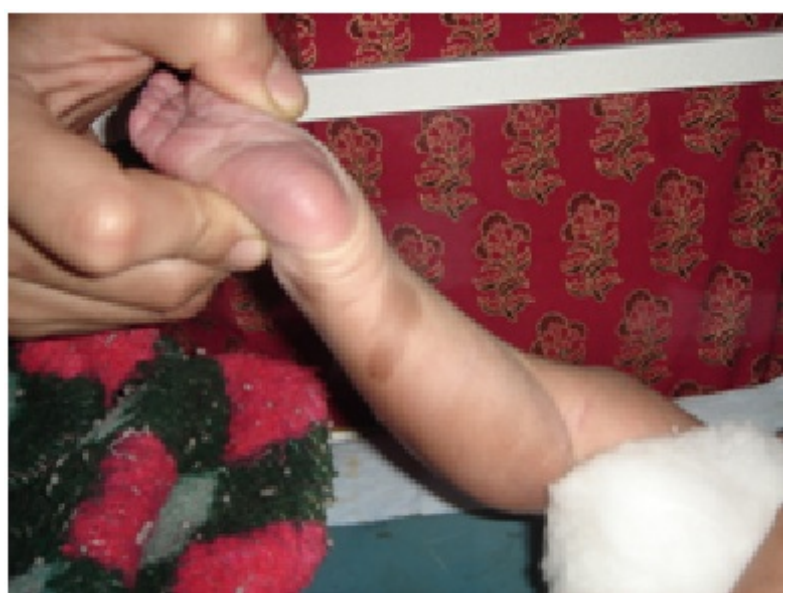

Figure 3. Large café au lait macule in the new born.

\section{Discussion}

NF1 is essentially full penetrant but there is considerable variation in the clinical features of the disease even in a single family [8]. In the present case also, she is the only one suffering from neurofibromatosis among her 4 
siblings. Her living son also had no evidence of the disease. A possibility of reciprocal adverse effects exists between disease and pregnancy. Pregnancy induces rapid progression of lesions, appearance of new lesions, more chances of complications and sarcomatous change [9]. In present case also, the lesions progressed in size and number during pregnancy and regressed in size post-natally.

There are 2 types of plexiform neurofibromas, nodular and diffuse. Diffuse one is also known as elephantiasis neurofibromatosa [10]. Plexiform neurofibromas involving the genitourinary tract or the lower limb are rare, with bladder, upper urinary tract and genital involvement reported in decreasing order of frequency [11] [12]. Studies have shown that in cases of genital NF1, vulva appears to be the most frequently affected with rare reports of vagina, cervix and ovary [13].

NF1 leads to increased chances of preeclampsia, eclampsia, intrauterine growth retardation, spontaneous abortion, still birth, oligohydramnios and perinatal mortality [7]. Our patient had no antenatal records to prove antenatal complications except for her blood pressure on admission was 146/90 mm of $\mathrm{Hg}$ and she had a history of stillbirth in the past. Very rarely, severe disease at birth is incompatible to life as may be was there in this case where the newborn was having NF1 and died on $4^{\text {th }}$ day of life. Though, we need more evidence to prove that NF1 itself lead to neonatal death. There have been case reports showing congenital generalized neurofibromatosis to be associated with poor prognosis and mortality rate of $92 \%$. Survivors were reported to develop serious sequelae (e.g. progressive growth of neurofibromas within neck and mediastinum leading to increasing airway obstruction and death; an enlarging proptotic and glaucomatous eye; and occurrence of brain and malignant nerve sheath tumors) especially when there was a strong family history of NF1 [14].

The management is mostly targeted on relieving the symptoms. Surgical excision is the main treatment choice as was offered in our patient. However, the results of surgical excision can be poor and procedure can be complicated due to size, location, vascular status, neural involvement, microscopic extension of the tumor and high rate of tumor re-growth.

\section{Conclusion}

We presented a rare case of NF1 with huge neurofiroma at an unusual site in pregnancy leading to adverse perinatal outcome. As the patient was of poor socioeconomic status she did not seek treatment in spite of her suffering. Prenatal diagnosis of NF1 has a future and can improve the pregnancy outcome. We suggest that all the pregnancies with neurofibromatosis should be considered to be high risk and closely monitored for any complications.

\section{References}

[1] Listernick, R. and Charrow, J. (2008) The Neurofibromatoses. In: Wolff, K., Goldsmith, L., Katz, S., Gilchrest, B., Paller, A. and Leffell, D., Eds., Fitzpatrick’s Dermatology in General Medicine, 7th Edition, McGraw Hill, New York, 1331-1339.

[2] (1988) Neurofibromatosis. Conference Statement. National Institutes of Health Consensus Development Conferences. Archives of Neurology, 45, 575-578.

[3] Ferner, R.E., Huson, S.M., Thomas, N., Moss, C., Willshaw, H., Evans, D.G., et al. (2007) Guidelines for the Diagnosis and Management of Individuals with Neurofibromatosis 1. Journal of Medical Genetics, 44, 81-88. http://dx.doi.org/10.1136/jmg.2006.045906

[4] (1988) National Institutes of Health Consensus Development Conference Statement Neurofibromatosis. Bethesda, Md., USA, July 13-15, 1987. Neurofibromatosis, 1, 172-178.

[5] Blickstein, I., Lancet, M. and Shoham, Z. (1988) The Obstetric Perspective of Neurofibromatosis. American Journal of Obstetrics \& Gynecology, 158, 385-388. http://dx.doi.org/10.1016/0002-9378(88)90160-3

[6] Segal, D., Holcberg, G., Sapir, O., Sheiner, E., Mazor, M. and Katz, M. (1999) Neurofibromatosis in Pregnancy. Maternal and Perinatal Outcome. European Journal of Obstetrics \& Gynecology and Reproductive Biology, 84, 59-61. http://dx.doi.org/10.1016/S0301-2115(98)00255-3

[7] Terry, A.R., Barker 2nd, F.G., Leffert, L., Bateman, B.T., Souter, I. and Plotkin, S.R. (2013) Neurofibromatosis Type 1 and Pregnancy Complications: A Population-Based Study. American Journal of Obstetrics \& Gynecology, 209, 46.e146.e8.

[8] Quintáns, B., Pardo, J., Campos, B., Barros, F., Volpini, V., Carracedo, A., et al. (2011) Neurofibromatosis without Neurofibromas: Confirmation of a Genotype-Phenotype Correlation and Implications for Genetic Testing. Case Reports in Neurology, 3, 86-90. http://dx.doi.org/10.1159/000327557 
[9] Isikoglu, M., Has, R., Korkmaz, D. and Bebek, N. (2002) Plexiform Neurofibroma during and after Pregnancy. Archives of Gynecology and Obstetrics, 267, 41-42. http://dx.doi.org/10.1007/s004040100239

[10] Harper, J.I. (1998) Genetics and Genodermatoses. In: Champion, R.H., Burton, J.L., Burns, D.A. and Breathnach, S.M., Eds., Text book of Dermatology, 6th Edition, Blackwell Science, Oxford, 378-384.

[11] Rekha, A. and Gopalan, T.R. (2006) Von Recklinghausen Neurofibromatosis-Pachydermatocele Causing Lower Limb Gigantism: A Case Report. International Journal of Lower Extremity Wounds, 5, 61-63. http://dx.doi.org/10.1177/1534734606286469

[12] Kaefer, M., Adams, M.C., Rink, R.C. and Keating, M.A. (1997) Principles in Management of Complex Pediatric Genitourinary Plexiform Neurofibroma. Urology, 49, 936-940. http://dx.doi.org/10.1016/S0090-4295(97)00098-8

[13] Gordon, M.D., Weilert, M. and Ireland, K. (1996) Plexiform Neurofibromatosis Involving the Uterine Cervix, Endometrium, Myometrium, and Ovary. Obstetrics \& Gynecology, 88, 699-701. http://dx.doi.org/10.1016/0029-7844(96)00242-6

[14] Isaacs Jr., H. (2010) Perinatal Neurofibromatosis: Two Case Reports and Review of the Literature. American Journal of Perinatology, 27, 285-292. http://dx.doi.org/10.1055/s-0029-1241737 